\title{
Bile acids differentially impact on platelet activation
}

\author{
J Tan ${ }^{1 *}$, E Reddy ${ }^{2}$ D Murphy², S Keely ${ }^{3}$, S O'Neill ${ }^{2}$ \\ From International Conference for Healthcare and Medical Students 2011 \\ Dublin, Ireland. 4-5 November 2011
}

\section{Introduction}

Platelets are well-established mediators of inflammatory responses throughout the body. Increased platelet activity occurs in the intestinal mucosa in conditions of Inflammatory Bowel Disease (IBD), where it may contribute to the mucosal fibrosis associated with these diseases. The bile acids, ursodeoxycholic acid (UDCA), deoxycholic acid (DCA) and tauroursodeoxycholic acid (TUDCA) were shown to regulate inflammatory responses in the intestine. The aim of this study is to analyse the impact of these bile acids on platelet activation.

\section{Methods}

Gel-filtered platelets were isolated from human blood. They were incubated with bile acids as follows: UDCA $(250 \mathrm{mM}$, $175 \mathrm{mM}, 100 \mathrm{mM}, 10 \mathrm{mM})$; DCA and TUDCA $(500 \mathrm{mM}$, $100 \mathrm{mM}, 10 \mathrm{mM}$ ) for 10 minutes at $37^{\circ} \mathrm{C}$ before activation with thrombin $(0.1 \mathrm{U} / \mathrm{ml})$ and collagen $(38 \mathrm{mg} / \mathrm{ml})$. The effects of the bile acids on platelet aggregation were examined using light transmission platelet aggregometry. Bile acid effects on platelet ADP secretion were assessed by measuring the level of luminescence from a luciferinluciferase 96 well-based assay. Effects of the bile acids on platelet morphology were examined by confocal microscopy. An MTT (3-(4,5-Dimethylthiazol-2-yl)-2,5-diphenyltetrazolium bromide)-based assay was used to assess the effects of the bile acids on platelet viability.

\section{Results}

UDCA inhibited platelet aggregation and ADP secretion in platelets activated with collagen, but not thrombin, in a concentration-dependent manner $(n=4, p<0.05)$. However, DCA and TUDCA inhibited platelet aggregation and ADP secretion in platelets activated with either agonist $(\mathrm{n}=4, \mathrm{p}<0.05)$. Confocal microscopy revealed decreased adhesion of platelets to collagen with increasing bile acid concentrations. However, UDCA had no effect on the adhesion of thrombin $(0.1 \mathrm{U} / \mathrm{ml})$-activated platelets to collagen. On the other hand, the presence of DCA and TUDCA reduced the adhesion of thrombinactivated platelets to collagen. MTT assays showed no significant effect of the bile acids on platelet viability.

\section{Conclusions}

While the effects of DCA and TUDCA appear to be more global on platelet activation, the effects of UDCA are more specific towards collagen activation of platelets. While the mechanisms involved remain unknown, these results indicate UDCA may specifically act as an antagonist to the collagen receptor, a2b1. Such actions of UDCA could have important implications for therapeutically reducing thrombotic/fibrotic events in patients with IBD.

\section{Author details \\ ${ }^{1}$ Royal College of Surgeons in Ireland, Ireland. ${ }^{2}$ Molecular and Cellular Therapeutics, Royal College of Surgeons in Ireland, Ireland. ${ }^{3}$ Molecular Medicine, Royal College of Surgeons in Ireland, Ireland.}

Published: 9 July 2012

doi:10.1186/1753-6561-6-S4-P22

Cite this article as: Tan et al:: Bile acids differentially impact on platelet activation. BMC Proceedings 2012 6(Suppl 4):P22.

${ }^{1}$ Royal College of Surgeons in Ireland, Ireland

Full list of author information is available at the end of the article

(c) 2012 Tan et al; licensee BioMed Central Ltd. This is an Open Access article distributed under the terms of the Creative Commons 